\title{
AVALIAÇÃO DA INTERAÇÃO ENTRE SUJEITOS EM DIFERENTES FAIXAS ETÁRIAS E MANUAL DE INSTRUÇÕES DE APARELHOS CELULARES
}

\section{EVALUATION OF THE INTERACTION BETWEEN INDIVIDUALS OF DIFFERENT AGE GROUPS AND THE INSTRUCTION MANUAL OF MOBILE DEVICES}

\author{
Vania Eugênia da Silva* E-mail: vania.eugenia@ufv.br \\ Amelia Carla Sobrinho Bifano* E-mail: abifano@ufv.br \\ Luciana Aparecida de Oliveira* E-mail: luolijsc@yahoo.com.br \\ Lígia Cristina Oliveira Roberto* E-mail: ligiacristina22@yahoo.com.br \\ Eloíse Garcia Ferreira*E-mail: eloisegf@gmail.com \\ * Universidade Federal de Viçosa (UFV), Viçosa, MG
}

\begin{abstract}
Resumo: Os manuais de instruções necessitam conter informações que protejam as empresas de usos "imprevistos" e de riscos de acidentes e, ao mesmo tempo, fornecer informações que contemplem as necessidades dos usuários e de contextos de utilização, garantindo o uso seguro e eficiente do produto. Este estudo avaliou a interação entre sujeitos pertencentes a diferentes faixas etárias e o manual de instruções de aparelhos celulares. $O$ trabalho foi executado pelo método desenvolvido pela equipe do Laboratório Interfaces para "Avaliação da usabilidade das interfaces em produtos eletroeletrônicos", composto por duas etapas: Avaliação heurística e Teste de precisão das ações. Foram avaliados manuais de instruções de sete marcas de aparelhos. Para a avaliação do produto, a amostra foi constituída por seis indivíduos, três do sexo masculino e três do sexo feminino, nas seguintes faixas etárias: menos de 25 anos, entre 25 e 50 anos e acima de 50 anos. A falta de informações e incapacidade das figuras foram as causas dos sujeitos não conseguirem entender ou para o alto nível de compreensão errada de certos procedimentos operacionais. Muitos dos termos técnicos eram desconhecidos para os indivíduos, o que causaram problemas para distinguir características indicadas no procedimento, evitando que o usuário explorasse as várias opções que o produto oferecia. As informações, às vezes, apresentada como imprecisa se caracterizava como incompreensíveis, ou difíceis de entender. Um Manual de Instruções deve conter informações suficientes para que o usuário possa utilizar o produto com eficiência e segurança.
\end{abstract}

Palavras-chave: Interação. Manuais de instruções. Usabilidade. Aparelho celular. Faixa etária.

\begin{abstract}
The owner instruction need to contain information for protect the companies as well as the users to the risk of accidents. Also as to provide information that address the needs of users into the usage contexts, ensuring the safe and efficient use of the product. This study evaluated the interaction between the owner instruction of mobiles devices and individuals of different ages. The procedure adopted as a method was developed by Interfaces Laboratory staff for "Usability evaluation of interfaces in consumer electronics products". It consists of two steps: heuristic evaluation and accuracy evaluation with which actions are performed. Was evaluated owner instructions of seven products. For the product evaluation, the sample consisted of six individuals, three of the male and three female genres, in the following age ranges: less than 25 years, between 25 and 50 years and above 50 years. Missing information and disability to the figures were the causes of the subjects failed to understand or to the high level of misunderstanding certain operating procedures. Many of the technical terms were unknown to the individuals, which caused trouble distinguishing features indicated in step procedure, preventing the user to explore the various options that the product offers. The information, sometimes presented as inaccurate if characterized as incomprehensible, they are
\end{abstract}

Revista Produção Online, Florianópolis, SC, v. 16, n. 2, p. 441-474, abr./jun. 2016. 
difficult to understand. An owner Instruction must contain sufficient information to enable the user to use the product efficiently and safely.

Keywords: Interaction. Owner manuals. Usability. Mobile. Age group.

\section{INTRODUÇÃO}

O advento da globalização trouxe consigo inúmeras transformações no campo político, econômico e social. O fluxo de informação aumentou e tornou-se mais rápido, permitindo aos cidadãos se informarem melhor e de forma mais rápida. Com isso, os cidadãos tornaram-se mais exigentes, pois passaram a conhecer melhor os seus direitos. Houve avanço na industrialização, refletindo na melhoria da qualidade de vida da sociedade e, consequentemente, aumentando a expectativa de vida.

Num mercado cada vez mais competitivo e globalizado, o surgimento de novos produtos que atendam às necessidades dos consumidores e/ou usuários se torna um desafio para as empresas garantirem sua permanência no mercado (MACHADO, ENSSLIN, 2012; AGUIAR, 2004). É fato que as novas tecnologias trazem ganhos de satisfação para o usuário/consumidor, mas, podem, ao mesmo tempo, frustrar os usuários/consumidores por não conseguirem alcançar os objetivos pretendidos com a utilização. Como as empresas pretendem desenvolver produtos que possam ser utilizados por uma gama de sujeitos e em contextos diversos, este sempre apresentará limitações, conforme pode ser evidenciado pelo número crescente de reclamações feitas aos Centros de Atendimento (0800, 0300 e internet) por usuários/consumidores que não conseguem usar seus produtos devido à sua complexidade (AGUIAR, 2004).

Para que sejam adequados e atendam melhor aos diferentes usuários, os produtos precisam atender à alguns requisitos do projeto tais como: a tarefa, a segurança, o conforto, o estereótipo popular, o envoltório de alcances físicos, a postura, a aplicação da força, os materiais. Para Aguiar (2004), a tarefa é o conjunto de ações humanas que permitem ao sistema atingir um objetivo. Os problemas ergonômicos decorrentes desse requisito estão relacionados a fatores que podem trazer dificuldades ao usuário para utilizar um produto em relação a suas características antropométricas, sexo, grau de instrução, experiência anterior, idade, 
habilidades especiais, assim como as ações relacionadas à interface usuárioproduto (GOMES FILHO, 2012).

De acordo com Gouvinhas; Ribeiro e Romeiro Filho (2001), os usuários podem ser considerados como consumidores em potencial, principalmente de produtos eletroeletrônicos, os quais devem facilitar o desempenho funcional dos usuários, garantindo uma maior independência e autonomia dos mesmos ao realizar suas atividades cotidianas.

Constitui-se, então, um dos desafios da sociedade e do mercado oferecer a esse público, bens e serviços que considerem suas limitações. Ou seja, colocar no mercado produtos duráveis, de fácil uso e compreensíveis, que tenham utilidade e atenda aos critérios de usabilidade.

O desenvolvimento de interfaces com boa usabilidade proporciona satisfação ao usuário, uma vez que ele conseguirá atingir seus objetivos com menos esforços e com mais facilidade (AGUIAR, 2004).

Para Moraes, Melo e Macário (2003), cabe aos ergonomistas a tarefa de analisar, tanto os produtos, como também seus manuais de instrução, pois trata-se de importante ferramenta, principalmente, quando o sujeito não possui as informações necessárias para o manuseio dos mesmos, ou apresenta algumas limitações físicas, motoras e audiovisuais, sejam estas em qualquer faixa etária.

Diante disso, justifica-se a importância desse estudo, pautado na necessidade de evidenciar que todos os sujeitos, independente de classe, raça, idade, sexo ou religião tenham acesso a produtos de qualidade que ofereçam satisfação ao realizarem suas tarefas e atividades diárias.

Teve-se como objetivo geral identificar, logo na primeira experiência de uso do produto, aspectos da interface dos manuais de instruções e guias de uso, quando pertinente, que pudessem contribuir para a dificuldade ou a não utilização do produto ou de alguma funcionalidade específica ou que conduzissem a riscos de acidentes ao usuário no decorrer da utilização.

Trata-se de um estudo qualitativo, realizado com sete modelos e marcas diferentes de aparelhos celulares. A definição dos participantes seguiu o recomendado pela ISOguide 37 (1995). De acordo com os requisitos do projeto, foram selecionados seis sujeitos para cada aparelho, sendo que estes obedeceram aos requisitos de sexo e idade. A pesquisa foi realizada no Laboratório Interfaces, da Revista Produção Online, Florianópolis, SC, v. 16, n. 2, p. 441-474, abr./jun. 2016. 
UFV - Universidade Federal de Viçosa, Viçosa, Minas Gerais, no período de fevereiro a agosto de 2009.

\section{REVISÃO BIBLIOGRÁFICA}

\subsection{Usabilidade}

A usabilidade é definida como a efetividade, a eficiência e a satisfação com que usuários particulares atingem objetivos específicos em ambientes também específicos, quando utilizam determinado produto ou serviço (ISO 9241-11 apud MARTINEZ, 2003; PINHEIRO, 2003; TORRES; MAZZONI 2004; VEGUINI, 2012; SOUZA; OLIVEIRA; BIFANO, 2013).

Bevan e Macleod (1994, apud Pinheiro, 2003) discute a ISO 9126, que referese à usabilidade enquanto capacidade de um software de ser compreendido, aprendido, utilizado e ser atrativo para o utilizador, em condições específicas de utilização.

Para Pinheiro (2003), as ISO's enfatizam os atributos internos e externos do produto que contribuem com a sua usabilidade, funcionalidade e eficiência, assim como, na qualidade de utilização, referindo-se desde como o utilizador realiza efetivamente as tarefas específicas em cenários específicos. Para o autor, a usabilidade depende tanto do produto como do usuário, ou seja, a usabilidade de um produto está intimamente relacionada com a capacidade de ser utilizado, compreendido por pessoas e situações particulares.

Assim, a usabilidade está relacionada ao grau de facilidade de interação do usuário com algum produto, independente de ser um produto ao qual esteja familiarizado (TORRES; MAZZONI, 2004).

Segundo Winckler e Pimenta (s.d.) e Souza, Oliveira e Bifano (2013), deve-se considerar que a usabilidade está relacionada a algumas questões, tais como o tipo de aplicação/uso, o perfil dos usuários, o contexto de utilização, dentre outras variáveis. Por outro lado, essas questões podem se modificar ao longo dos anos, em função do crescimento da população usuária, mudança dos requisitos e recursos da aplicação e mesmo atualização da tecnologia. 
Conforme Pinheiro (2003), a usabilidade foca o campo da interação usuáriomáquina, fazendo a ligação entre as pessoas e as máquinas. Essa interação com o usuário ocorre a partir de dispositivos de saída e de entrada das máquinas e do conhecimento e experiência do usuário.

Jordan (1998, apud Moraes, Melo e Macário, 2002) acrescenta que a eficiência da interação usuário/máquina está no fato de a pessoa atingir o objetivo, ou seja, cumprir a tarefa implicada na interpretação humano-máquina objetivamente. Já a eficácia consiste no volume de trabalho que o usuário alcança com o nível mínimo de erro. E o que traz satisfação é o grau de conforto que o usuário sente ao usar um determinado produto atingindo seu objetivo.

Considerando então a interação homem-máquina como foco de usabilidade, tem-se que a mesma está relacionada à eficácia e à eficiência da interface diante do usuário e pela reação do usuário diante da interface (FERREIRA, 2002).

Macleod (1994, apud Dias, s.d.) considera a usabilidade uma "qualidade de uso, e interação entre usuário e sistema". E essa interação depende das características do sistema e do usuário. Em suma, o autor enfatiza que, o resultado dessa interação pode ser bom para alguns e ruim para outros. Portanto, deve-se considerar também que a usabilidade depende das tarefas específicas que os usuários realizam dentro do sistema, assim como do ambiente físico (incidência de luz, barulho, interrupções da tarefa, disposição do equipamento, dentre outros). Logo, a usabilidade é uma qualidade de uso de um sistema, diretamente associada ao seu contexto operacional e aos diferentes tipos de usuários, tarefas, ambientes físicos e organizacionais. Com isso, pode-se considerar que qualquer modificação em algum aspecto relevante do contexto de uso é capaz de alterar a usabilidade de um sistema, envolvendo o homem e a máquina.

\subsection{A Ergonomia na concepção de produtos com maior usabilidade}

Algumas limitações apresentadas por sujeitos usuários de produtos, juntamente com projetos de produto mal concebidos podem levar ao mau uso dos equipamentos, ou até mesmo contribuir para a ocorrência de acidentes domésticos.

Considerando estes aspectos, lida (2005) discute que a aplicação da ergonomia aos projetos dos objetos e ambientes requer um conhecimento melhor 
dos sujeitos que utilizarão o produto. De modo que, a adoção de produtos ergonômicos sirva para a reabilitação e a adaptação dos mesmos, tornando-os indivíduos mais satisfeitos, produtivos e com melhor qualidade de vida.

Ressalta-se que, a ergonomia deve ser considerada em todos os produtos, sejam de grande ou pequeno porte, de tecnologia simples ou complexa, projetados com o propósito de satisfazer as necessidades humanas (IIDA, 2005).

A concepção de um novo produto baseia-se, conforme Gouvinhas; Ribeiro e Romeiro Filho (2001), no design universal, que é um movimento mundial que considera todos os produtos, sejam esses, ambiente e meios de comunicação, entre outros aspectos do cotidiano das pessoas, concebidos com o intuito de atender às necessidades de um maior número possível de usuário, onde os idosos se incluem.

Os produtos são considerados como meios para que o homem possa executar determinadas funções. Sendo assim, torna-se necessária, conforme coloca Canciglieri Junior et al. (2007), a incorporação de conceitos de ergonomia e usabilidade no desenvolvimento de produtos, e, sobretudo, em produtos customizados para grupos especiais de usuários, para que esses possam melhorar a interface usuário-produto, de forma a favorecer a todas as funções que lhe são necessárias.

Pois, de acordo com Bifano e Simão (2003), uma das dificuldades enfrentadas na concepção dos produtos é conseguir um número de características que torne possível a diferentes indivíduos compreender, operar e extrair o máximo de utilidade de um produto ao adquiri-lo. As autoras ainda acrescentam que, as pesquisas de interface e usabilidade comprovam que a maneira como os produtos são concebidos não corresponde à forma como os indivíduos os utilizam, uma vez que estes possuem mecanismos próprios de ação, e esta ação é situada, ou seja, depende do contexto no qual se desenvolve a tarefa.

Segundo Bifano (2001), a incompreensão das informações de uso ou as dificuldades de interação de alguns grupos de usuários com o produto não são percebidas pelos projetistas como problemas relacionados à incapacidade ou limitações do produto e da equipe de Pesquisa e Desenvolvimento (P\&D), mas sim da incapacidade cognitiva do usuário para utilizar o produto. Moraes, Melo e Macário (2004) acrescentam que, isso se deve ao fato de os engenheiros não conceitualizarem as informações com a mesma linguagem dos usuários.

Revista Produção Online, Florianópolis, SC, v. 16, n. 2, p. 441-474, abr./jun. 2016. 
Para Glushko e Bianchi (1982, apud Moraes, Melo e Macário, 2004), as empresas precisam entender que os requisitos para uma boa interação começam com um planejamento de conteúdo bem feito.

Existem inúmeros fatores que podem influenciar negativamente um indivíduo ao usar seu produto, por exemplo: dimensões mal planejadas, má configuração, inconsistência das funções atribuídas ao mesmo, comandos mal posicionados ou projetados, entre outros. Há ainda quem recorra aos manuais de instrução. No entanto, estes podem apresentar problemas de interpretação bem como de informações gerando pouca compreensão das mesmas, incompatibilidade entre a quantidade de informações, legibilidade, entre outros pontos que poderiam ser evidenciados, considerando a análise dos manuais de instrução. Em função disso, em qualquer momento durante o uso poderá haver a ocorrência de acidentes ou incidentes, se o produto não oferecer a segurança necessária aos usuários. O mesmo ocorrerá se o manual de instrução não for bem claro.

Segundo Carpes Jr e Sell (2004), a interação entre usuário e produto são complexas e perigosas, tornando-se um desafio para projetistas. Para eles os mesmo devem considerar aos aspectos ergonômicos, assim como fazer uma boa distribuição de tarefas entre produto e usuário para que se possa garantir uma interação adequada em uso.

\subsection{Manuais de instruções}

Aliado à complexidade de utilização dos produtos soma-se a baixa qualidade das informações contidas em embalagens, manuais de instrução e guias de uso que acompanham alguns produtos (BIFANO 2000; 2001; 2013; BIFANO; SZNELWAR, 2004; BIFANO, et al., 2009). Especificamente, no caso dos manuais de instruções, problemas relacionados à compreensibilidade, à significação das mensagens, à compatibilidade entre a quantidade e legibilidade das informações ou a sua ausência, dentre outros, fazem com que para o usuário/consumidor, seja muito difícil ou impossível, em alguns casos, usar o produto de maneira segura e satisfatória em termos de alcance dos resultados pretendidos (SILVA; BIFANO; ROCHA, 2009).

Para Bifano (2000, 2013) e Bifano et al. (2009), o problema não está apenas nas instruções, mas também, nas interpretações e incertezas de uso em situações 
particulares. Aguiar (2004) complementa ressaltando a necessidade de se considerar níveis de experiência diversos entre usuários/consumidores: alguns já utilizaram um produto semelhante; outros não têm nenhuma experiência com determinado produto, como também a utilização tanto de uma lógica de utilização (o usuário/consumidor visa os objetivos e procura os meios para atingi-los) quanto de uma lógica de funcionamento (as regras de desenvolvimento das funcionalidades previstas no produto) na consecução de seus objetivos. A interação dessas duas lógicas, na apresentação do manual, é uma das fontes mais frequentes de dificuldades para os usuários/consumidores. Segundo Bifano (2001), outro fator relacionado à compreensão das informações, é a questão da polissemia da linguagem, ou seja, a possibilidade de interpretações variadas de acordo com quem as lê. Dessa forma, instruções elaboradas a partir da compreensão dos processos relacionados à aprendizagem dos indivíduos e de uma preocupação com a forma de apresentação das informações terão maiores chances de alcançarem êxito em suas pretensões iniciais. Para Wright (1981), na elaboração de instruções adequadas é necessário avaliar a adequação do conteúdo, da apresentação, da estrutura e a qualidade do escritor.

Por meio dos estudos de Amaral Junior (2012), Oliveira e Bifano (2014), Neves e Bifano (2015) com usuários idosos, foi possível perceber a necessidade de os manuais apresentarem suas informações em forma de comando, explicando os significados dos termos complexos e em outros idiomas e, em sequência, que facilite a utilização do produto pelo usuário. Os autores identificaram que somente o preconizado pelas normas não é suficiente para que os manuais sejam adequados, para eles é preciso entender a lógica de utilização dos usuários em seu cotidiano, ou seja, é preciso estudar o uso dos produtos no cotidiano de forma a subsidiar os projetistas a produzirem manuais com maior compreensibilidade, assim como considerar as características particulares de cada usuário.

Em síntese, pode-se afirmar que o que se espera de um Manual de Instruções é que este contenha informações suficientes para que o usuário/consumidor possa operar/utilizar o produto adquirido com eficiência e segurança. 


\section{PROCEDIMENTOS METODOLÓGICOS}

Foram avaliados manuais de instruções de sete aparelhos celulares de diferentes marcas, quais sejam: Alcatel, Intelbrás, LG, Motorola, Nokia, Samsung e Sony Ericsson, seguindo o método desenvolvido pela equipe do Laboratório Interfaces para "Avaliação da usabilidade das interfaces em produtos eletroeletrônicos", cuja estrutura é descrita a seguir:

\subsection{Avaliação heurística}

Inicialmente, o termo "avaliação heurística" foi utilizado por Nielsen e Molich (1990), em testes de usabilidade para softwares e requisitos computacionais. Estes autores formularam um conjunto de princípios - por eles denominadas heurísticas que seriam a base de análise de usabilidade de todo produto.

No entanto, apesar da semelhança semântica, o sentido atribuído no método do Laboratório Interfaces para avaliação heurística é outro. Diferente da proposta de Nielsen e Molich, esta avaliação não está pautada em um conjunto de heurísticas, mas na avaliação global do produto. O objetivo principal desta etapa na avaliação de um produto é permitir ao corpo de profissionais envolvidos no estudo a familiaridade com a tecnologia avaliada, tornando possível o reconhecimento das informações contidas no - e que acompanham - o produto, suas possibilidades e limitações de uso bem como os pontos críticos de sua utilização com relação à segurança ao usuário e à integridade de seu funcionamento. Esta etapa possibilita coletar os dados que subsidiam a elaboração dos roteiros para condução dos ensaios em laboratório.

\subsection{Ensaios de compreensão das informações}

Os ensaios se constituem de duas etapas: avaliação da "precisão das ações", ou seja, o quão possível é utilizar o produto com êxito em seu primeiro contato; e avaliação da compreensão das figuras e de termos técnicos identificados na avaliação heurística. 


\subsection{Estabelecimento do cadastro de voluntários}

Os cadastros foram feitos por meio de entrevistas por telefone, de forma aleatória. Os números de telefone foram selecionados por bairros considerados de classe média, alta e baixa. Seguindo o número de participantes indicado pela ISOguide 37 (1995) e os requisitos do projeto, foram selecionados seis sujeitos para cada aparelho, sendo que estes obedeceram aos requisitos de sexo e idade. Assim, o grupo se constituiu de sujeitos de ambos os sexos nas seguintes faixas etárias: dois sujeitos menores que 25 anos; dois sujeitos de 25 a 50 anos; e dois sujeitos acima de 50 anos, totalizando seis sujeitos por aparelho, de ambos os sexos.

Contou-se com a participação de sujeitos que já haviam tido experiências anteriores com o produto desde que não fosse aquele modelo para o qual seria convidado a participar dos ensaios e, sujeitos que não possuíam celular, isto é, não haviam tido contato com este tipo de produto. O objetivo deste critério foi avaliar a adequação das instruções a sujeitos de primeiro contato com o produto e de qualquer idade ou classe social. Após contato telefônico e aceite dos sujeitos a participarem dos trabalhos, agendou-se dia e horário de acordo com a disponibilidade de cada sujeito. Cada teste teve a duração média de três horas. Todos os ensaios foram registrados em DVD e depois transcritos para validarem as observações feitas no decorrer dos procedimentos. Os registros serviram também para reavaliação de situações que se apresentaram dúbias.

\subsection{Procedimentos para a condução dos ensaios}

\subsubsection{Teste de "precisão das ações"}

Para o teste de "precisão de ações" os sujeitos foram convidados a executar um conjunto de ações relacionadas à utilização do produto em suas funções básicas (montagem, acertar data e hora, chamada, contatos, identificação de chamadas, mensagem, controle de gastos e bloquear teclado) e demais funcionalidades existentes de acordo com cada modelo em estudo. O ensaio foi estruturado a partir de questões "Como eu faço para?". Os produtos foram entregues aos sujeitos em suas respectivas embalagens, e, a partir daí, era dada a seguinte situação: "Você 
ganhou este celular de presente e pretende mostrar ao seu filho, esposa, mãe, etc. Como você o faria?" Nesta fase observou-se a disponibilidade de informações na embalagem, nas etiquetas adesivas e nos demais materiais informativos a partir dos quais fosse possível ao sujeito identificar como abrir a embalagem, o que esta continha, o modelo e as funcionalidades do produto. A partir desta primeira fase, a orientação dada era a de tentar executar as ações solicitadas por meio de consultas ao manual de instruções e ao guia do usuário, quando fosse o caso.

Para a avaliação das ações, criou-se uma escala de pontuação composta pelas seguintes possibilidades de resposta do sujeito em interação com o produto: “nenhum erro", “menor erro" e "maior erro". Onde a categoria “nenhum erro" representa o êxito da ação do sujeito sobre o produto na primeira tentativa; "menor erro" representa uma compreensão não condizente com o pretendido pela equipe de projeto, mas que é, em seguida, corrigida pelo sujeito. No caso de "maior erro", o usuário, apesar de ler e tentar executar a ação várias vezes, desiste ou só consegue executá-la a partir do auxílio do técnico.

A utilização desta nomenclatura é baseada nos estudos desenvolvidos por Sinaiko (1975) para avaliar a precisão das ações executadas pelos trabalhadores na montagem de equipamentos complexos, comparando os resultados de eficiência em precisão de ações quando as atividades de montagem eram desenvolvidas com o auxílio e sem o auxílio das instruções escritas. Quanto menor a quantidade de problemas de compreensão as informações (verbais e não verbais) apresentassem, maior a probabilidade de ações precisas.

\subsubsection{Teste de compreensão de termos técnicos e figuras}

Foi apresentada ao participante uma lista de figuras, palavras, termos ou expressões extraídas dos textos dos manuais em questão, para as quais foi solicitado responder o que eles compreendiam. Utilizou-se uma escala de valores para as categorias: "Certo”, "Parcialmente certo", "Errado”, “Não sei”. Sendo que "Certo" designa a compreensão pelo sujeito do mesmo significado pretendido pela equipe de projeto; "Parcialmente Certo" quando a compreensão se dá parcialmente com relação à figura ou termo técnico, "Errado" e "Não sei" são consideradas respostas de não compreensão das figuras e/ou termos técnicos, sendo o termo

Revista Produção Online, Florianópolis, SC, v. 16, n. 2, p. 441-474, abr./jun. 2016. 
"Errado" utilizado pra designar a resposta que é completamente "fora" daquilo pretendido pela equipe - neste caso, o sujeito "chuta" uma resposta ou imagina um possível significado; já na resposta "Não sei" o sujeito assume a não compreensão da informação.

Após as simulações em laboratório, foram feitas as transcrições dos vídeos e a avaliação das ações, bem como das problemáticas de utilização. A dinâmica da interação tornou possível avaliar se as instruções - na sua disposição, no conteúdo propriamente dito e na linguagem - foram suficientes para a condução de êxito nas ações.

\subsection{Procedimentos estatísticos para tratamento e apresentação dos dados}

As etapas foram organizadas em cinco grupos, cujas variáveis foram agrupadas em categorias e estão descritas respectivamente a seguir:

I. Conhecimento do produto: desembalagem, possibilidades de uso do aparelho;

II. Ações básicas: montagem, acertar data e hora, fazer uma chamada, contatos, identificação de chamadas, mensagem, controle de gastos, bloquear teclado (quando pertinente);

III. Outras funções do aparelho: calendário; despertador/alarme; MP3, MP4; gravador; rádio; câmera fotográfica; câmera filmadora; contador regressivo; cronômetro; controle do ciclo menstrual; desenho.

IV. Descarte e segurança no uso do produto: informações relacionadas à responsabilidade ambiental em termos do descarte do produto e de partes deste, como também informações relacionadas ao risco de incêndio, queimaduras e choques elétricos.

V. Interpretação de palavras, termos e figuras: as palavras e figuras utilizadas foram selecionadas a partir da avaliação heurística do produto.

Manuais de alguns fabricantes não apresentavam todas as categorias acima descritas sem, no entanto, prejudicar a avaliação da utilidade do manual. Para cada aparelho celular, o número de itens avaliados (a serem chamados, neste estudo, de 
variáveis) está relacionado ao número e detalhamento das informações contidas nos seus respectivos manuais.

Cada variável (informação contida no manual) foi avaliada (ou executada) e, de acordo com a resposta obtida, ou o procedimento executado, foram atribuídas notas na escala de 1 a 3, onde, exceto para a categoria FIGURAS, 1 = Nenhum erro, 2 = Menor erro, e $3=$ Maior erro. Para as variáveis relacionadas a figuras e desenhos, a codificação representava: $1=$ Certo, 2 = Errado, $3=$ Não sei, $4=$ Parcialmente certo.

Para atender à proposta deste estudo, os manuais e suas respectivas informações correlacionadas, foram avaliados separadamente, modelo por modelo. Portanto, os dados foram analisados descritivamente usando-se o programa Sistema para Análises Estatísticas - SAEG, desenvolvido na Universidade Federal de Viçosa. A apresentação descritiva final dos dados foi feita principalmente na forma de gráficos apresentados a seguir.

\section{RESULTADOS E DISCUSSÕES}

Como o estudo pretendia conhecer as limitações das informações, cada manual foi estudado separadamente e os dados foram analisados descritivamente. Foram obtidas frequências absolutas e relativas para cada aparelho celular.

\subsection{Teste de precisão das ações}

\subsubsection{Alcatel - OT E801}

A Figura 1 mostra a ocorrência de maior erro obtida para todas as faixas etárias participantes do estudo, ao utilizar o aparelho Alcatel, seguindo as instruções que o acompanham. 
Figura 1 - Número de ocorrências do grau de dificuldade (Valores Absolutos Percentuais) em todas as categorias obtidas no teste de precisão de ações para o celular ALCATEL para as faixas etárias: menor que 25 anos, entre 25 e 50 anos e acima de 50 anos

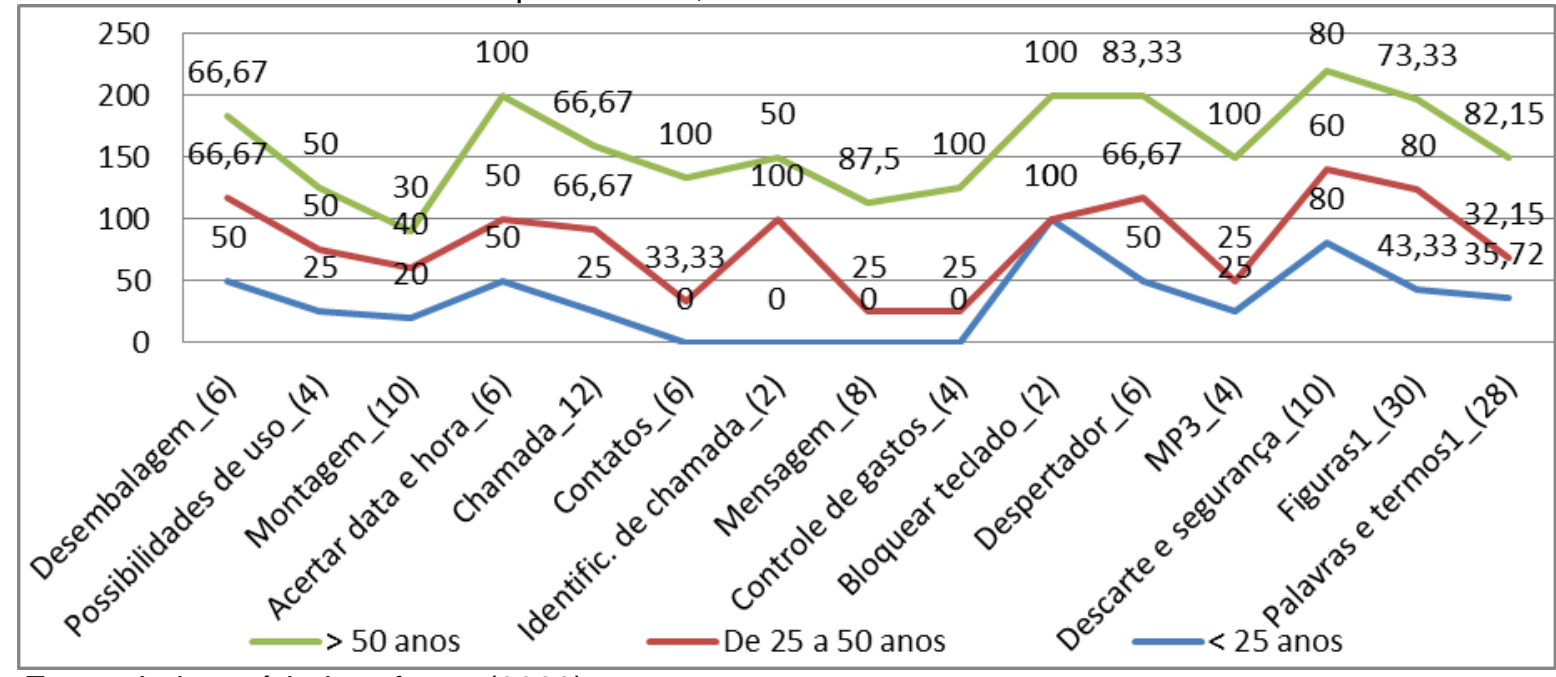

Fonte: Laboratório Interfaces (2009)

Pelos dados da Figura 1 observa-se que as categorias que apresentaram maiores índices de erro para a faixa etária menor que 25 anos foram "Desembalagem", "Acertar data e hora" e "Bloquear teclado" compreendidas nas categorias consideradas como "funcionalidades básicas". Dentre as categorias consideradas como "outras funcionalidades", as que mais se destacaram para a referida faixa etária foram "Despertador" e "Descarte e Segurança". Essas ocorrências de maior erro se deram em função da não localização da informação no manual, informações incompletas e até mesmo ausência de informações.

Para a faixa etária entre 25 e 50 anos, as ocorrências de maior erro dentro das categorias consideradas como "funcionalidades básicas" foram em relação à "Desembalagem", "Possibilidades de uso", "Acertar data e hora", "Chamada" e "Identificação de chamada". Já nas categorias consideradas como "outras funcionalidades", as ocorrências se deram em "Despertador", "Descarte e Segurança" e "Figuras". Na maioria dos casos, as ocorrências se deram pela não localização da informação no manual, informações incompletas, ausência de informações e não compreensão da informação fornecida pelo manual.

Já para a faixa etária acima de 50 anos, dentre as 15 categorias estudadas, cinco apresentaram $100 \%$ de maior erro, ou seja, em 33,33\% das categorias deste aparelho, os sujeitos com mais de 50 anos não conseguiram realizar nenhuma ação, 
seja por não compreensão da informação fornecida pelo manual de instrução, seja por não localização da informação no manual.

Silva, Bifano e Rocha (2009) argumentam que, no caso dos manuais de instruções, problemas relacionados à compreensibilidade, à significação das mensagens, à compatibilidade entre a quantidade e a legibilidade das informações ou a sua ausência, dentre outros, fazem com que para o usuário/consumidor, seja muito difícil ou impossível, em alguns casos, usar o produto de maneira segura e satisfatória em termos de alcance dos resultados pretendidos.

Pode-se perceber pelos dados apresentados na Figura 1, que o grau de dificuldade em relação ao uso do aparelho celular Alcatel acompanhado de suas respectivas instruções, aumentou conforme a faixa etária, isto é, os sujeitos com mais idade tiveram maiores dificuldades na interação com o aparelho e suas instruções.

Segundo Winckler e Pimenta (s.d.), isso se explica pelo fato de se considerar que a usabilidade está relacionada a algumas questões, tais como o tipo de aplicação/uso, o perfil dos usuários, o contexto de utilização, dentre outras variáveis. Por outro lado, essas questões podem se modificar ao longo dos anos, em função do crescimento da população usuária, da idade dos sujeitos usuários, mudança dos requisitos e recursos da aplicação e mesmo atualização da tecnologia.

Por outro lado, a dificuldade encontrada pelos sujeitos ao interagir com 0 aparelho e o manual de instrução, se deve à qualidade das informações contidas tanto na embalagem, produto e nas instruções do próprio manual, que se apresentam, muitas vezes, como imprecisas, incompletas ou mesmo ausentes.

\subsubsection{Intelbrás - M500}

A Figura 2 mostra a ocorrência de maior erro obtida para todas as faixas etárias participantes do estudo, ao utilizar o aparelho Intelbrás, seguindo as instruções que o acompanham. 
Figura 2 - Número de ocorrências do grau de dificuldade (Valores Percentuais) em todas as categorias obtidas no teste de precisão de ações para o celular INTELBRÁS, para as faixas etárias: menor que 25 anos, entre 25 e 50 anos e acima de 50 anos

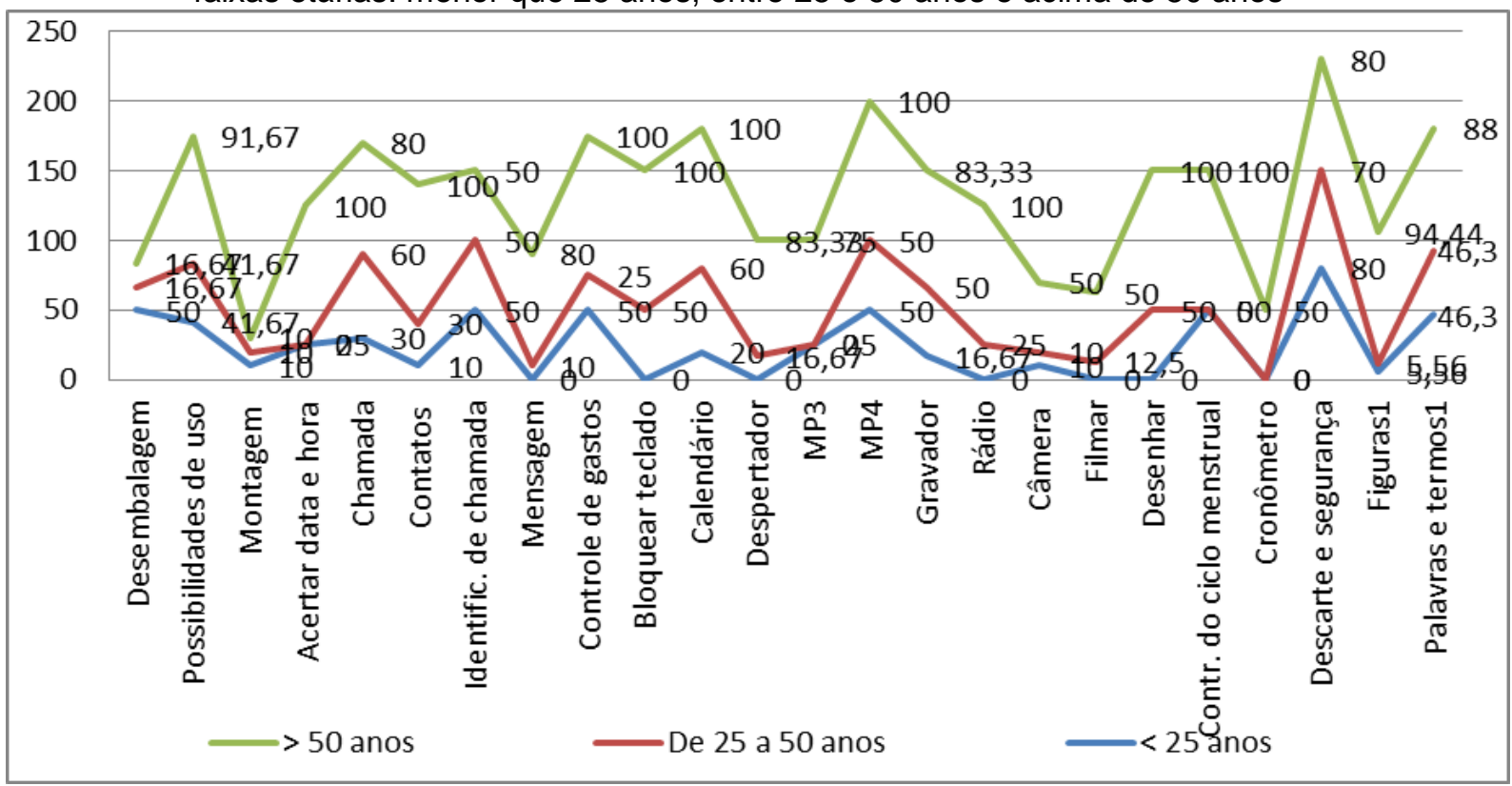

Fonte: Laboratório Interfaces (2009)

Pela Figura 2 observa-se que as categorias consideradas como "Funcionalidades básicas", a "Desembalagem", "Identificação de chamada" e "Controle de gastos" obtiveram $50 \%$ de maior erro cada uma, para a faixa etária menor que 25 anos. Esse percentual se deu em função da ausência de informação ou não localização da informação no manual por esta estar mal disposta no manual de instruções. Para as categorias consideradas como "Outras funcionalidades", os maiores percentuais de erro foram em relação à "MP4", "Controle do ciclo menstrual" e "Descarte e Segurança", pela utilização de termos técnicos desconhecidos pelos sujeitos, informações incompletas, não localização da informação e ausência de informação.

Dentre as 24 categorias analisadas para o aparelho Intelbrás, 22 apresentaram índices elevados de maior erro a partir de 50\%; nove categorias apresentaram índice máximo de erro (100\%) ao serem utilizadas pelos sujeitos compreendidos na faixa etária acima de 50 anos.

Entre as categorias consideradas como "funcionalidades básicas", a categoria "Contatos" merece destaque, pois nenhum dos sujeitos acima de 50 anos conseguiu usar esta função do aparelho devido a não localização da informação no manual, não compreensão da informação existente e/ou informação incompleta e, portanto, insuficiente para realização da ação.

Revista Produção Online, Florianópolis, SC, v. 16, n. 2, p. 441-474, abr./jun. 2016. 
Já entre as categorias consideradas como "outras funcionalidades" do aparelho, destacam-se as categorias "Calendário", "MP4", "Rádio", "Desenhar" e "Controle do ciclo menstrual" onde os sujeitos acima de 50 anos não conseguiram usar estas funções.

A maioria das ocorrências de maior erro para o aparelho Intelbrás se deu em função da não localização da informação no manual, provavelmente por estar mal localizada ou sem destaque para o usuário; colocação do cartão SIM de forma incorreta e; informação insuficiente para a execução das ações com êxito, além da não compreensão da informação quando existente e desistência do teste por não conseguir obter sucesso ao usar o aparelho.

Bifano (2001) explica que um dos fatores relacionados à compreensão das informações é a polissemia da linguagem, ou seja, a possibilidade de interpretações variadas de acordo com quem as lê. Dessa forma, instruções elaboradas a partir da compreensão dos processos relacionados à aprendizagem dos indivíduos e de uma preocupação com a forma de apresentação das informações terão maiores chances de alcançarem êxito em suas pretensões iniciais.

Com relação ao uso do aparelho celular Intelbrás, observa-se também que aumentou o grau de dificuldade conforme o aumento da idade. É preciso considerar que algumas limitações ocorrem com o passar dos anos, e estas podem ser físicas e/ou intelectuais.

Como limitações físicas pode-se citar, de acordo com Moraes, Melo e Macário (2004), a perda da audição e da visão, fragilidade dos ossos e da agilidade motora. Todos estes fatores contribuem para que o sujeito se sinta incapaz, gerando nele um sentimento de constrangimento, podendo afetar sua auto-estima, quando não se obtém êxito no uso de um produto.

Nesse sentido, as informações necessitam serem de fácil compreensão para garantir o uso eficiente e seguro do produto por sujeitos em qualquer faixa etária.

\subsubsection{LG - KP106}

A Figura 3 mostra a ocorrência de maior erro obtida para todas as faixas etárias participantes do estudo, ao utilizar o aparelho LG, seguindo as instruções que o acompanham. 
Figura 3 - Número de ocorrências do grau de dificuldade (Valores percentuais) em todas as categorias obtidas no teste de precisão de ações para o celular LG, e os respectivos Valores Percentuais, para as faixas etárias: menor que 25 anos, entre 25 e 50 anos e acima de 50 anos

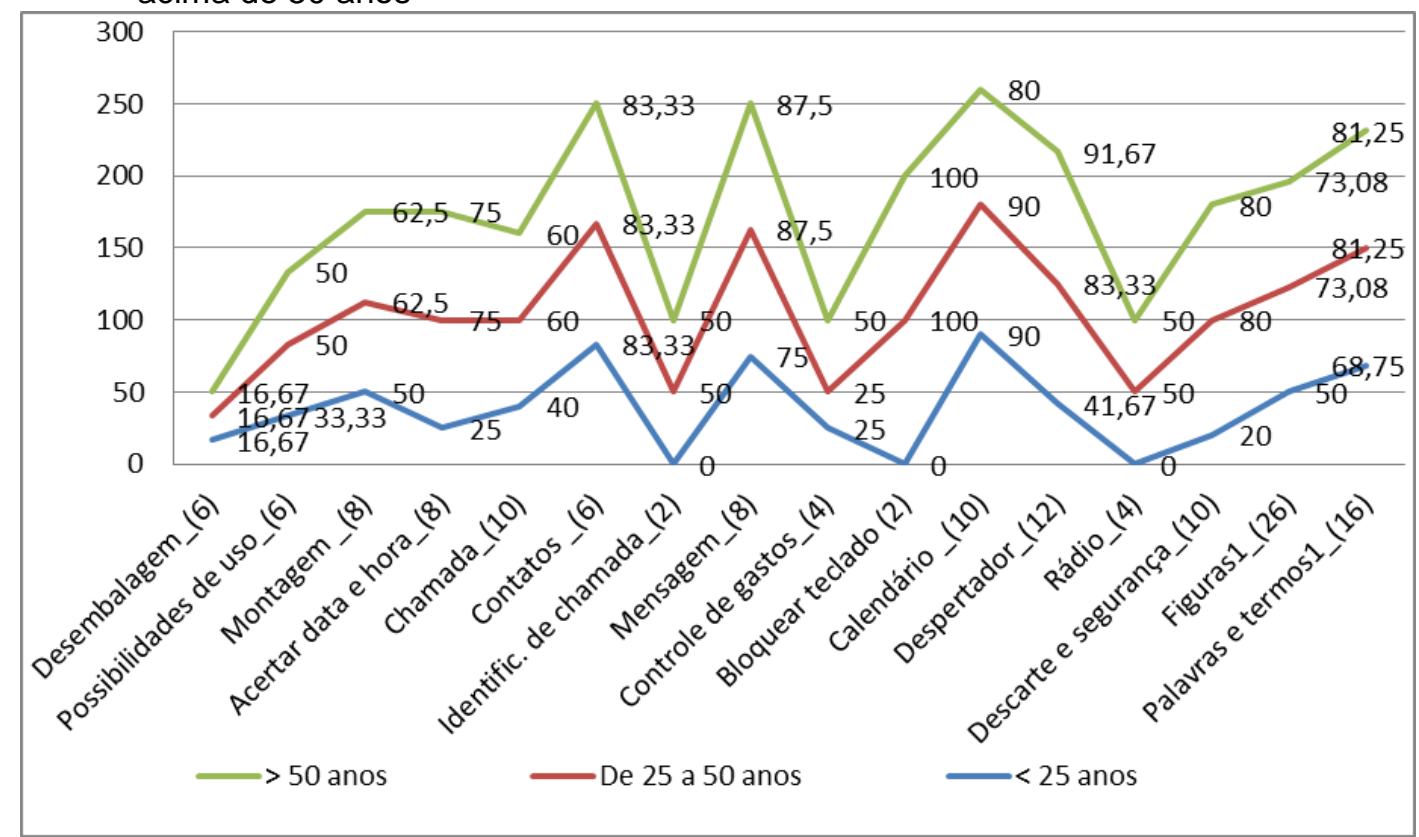

Fonte: Laboratório Interfaces (2009)

Os resultados acima demonstram as ocorrências de maior erro para a faixa etária menor que 25 anos, ao interagir com o aparelho LG, foram em relação às categorias "Montagem", "Contatos" e "Mensagem", consideradas como "funcionalidades básicas do aparelho", e, também, em relação às categorias consideradas como "outras funcionalidades", quais sejam, "Calendário", "Figuras" e "Palavras e Termos". As ocorrências de maior erro na interação com o aparelho LG se deram pela não localização da informação no manual de instruções, informações incompletas, não compreensão da informação existente ou ausência de informação.

Para a faixa etária entre 25 e 50 anos, as maiores ocorrências de erro foram em relação às categorias consideradas como "funcionalidades básicas", a saber: "Possibilidades de uso", "Montagem", "Acertar data e hora”, "Chamada”, "Contatos", "Identificação de chamada", "Mensagem" e "Bloquear Teclado". Algumas categorias consideradas como "outras funcionalidades" também obtiveram índices elevados de maior erro, quais sejam: "Calendário", "Despertador", "Rádio", "Descarte e Segurança", "Figuras" e "Palavras e Termos". Na maioria dos casos, a ocorrência de maior erro foram devido a não localização da informação no manual, não compreensão da informação disponível, informações incompletas, ou mesmo a ausência de informação.

Revista Produção Online, Florianópolis, SC, v. 16, n. 2, p. 441-474, abr./jun. 2016. 
Já em relação à faixa etária acima de 50 anos, os dados da Figura 3 mostram que das 16 categorias avaliadas para o aparelho LG, 15 apresentaram índices de maior erro a partir de $50 \%$. Dentre estas, a categoria "Bloquear teclado" foi a única a apresentar $100 \%$ de maior erro, para a referida faixa etária. Entretanto, categorias consideradas como "funcionalidades básicas" do aparelho "Contatos" e "Mensagem" obtiveram índices elevados de maior erro (83,33\% e $87,50 \%$, respectivamente). Esses percentuais podem ser explicados pela ausência de informação; informação insuficiente; não compreensão da informação pelos sujeitos; não localização da informação no manual e; colocação de forma incorreta do cartão SIM. A categoria "Descarte e Segurança" obteve $80 \%$ de maior erro, e esses erros se explicam pela ausência de informação e/ou não localização da informação no manual o que significa um fato preocupante, pois essas informações são imprescindíveis para um uso correto e seguro do aparelho.

Segundo Bifano (2001), a incompreensão das informações de uso ou as dificuldades de interação de alguns grupos de usuários com o produto não são percebidas pelos projetistas como problemas relacionados à incapacidade ou limitações do produto e da equipe de Pesquisa e Desenvolvimento (P\&D), mas sim da incapacidade cognitiva do usuário para utilizar o produto. Moraes, Melo e Macário (2004) acrescentam que isso se deve ao fato de os engenheiros não conceitualizarem as informações com a mesma linguagem dos usuários. Para Glushko e Bianchi (1982, apud Moraes, Melo e Macário, 2004), as empresas precisam entender que os requisitos para uma boa interação começam com um planejamento de conteúdo bem feito.

Pode-se perceber pelos dados da figura acima que o grau de dificuldade em relação ao uso do aparelho celular LG acompanhado de suas respectivas instruções, aumentou conforme a faixa etária, isto é, os sujeitos com mais idade tiveram maiores dificuldades na interação com o aparelho e seu manual de instrução.

De um modo geral, no aparelho LG observou-se, também, uma diferença acentuada de maior erro entre as faixas etárias: menor que 25 anos, de 25 a 50 anos e, de menor que 25 anos e acima de 50 anos. Por outro lado, as faixas etárias: de 25 a 50 anos e acima de 50 anos obtiveram praticamente o mesmo grau de dificuldade ao interagir com o aparelho LG.

Revista Produção Online, Florianópolis, SC, v. 16, n. 2, p. 441-474, abr./jun. 2016. 
A Figura 4 mostra a ocorrência de maior erro obtida para todas as faixas etárias participantes do estudo, ao utilizar o aparelho Motorola, seguindo as instruções que o acompanham.

Figura 4 -Número de ocorrências do grau de dificuldade (Valores Percentuais) em todas as categorias obtidas no teste de precisão de ações para o celular MOTOROLA, e os respectivos Valores Percentuais, para as faixas etárias: menor que 25 anos, entre 25 e 50 anos e acima de 50 anos

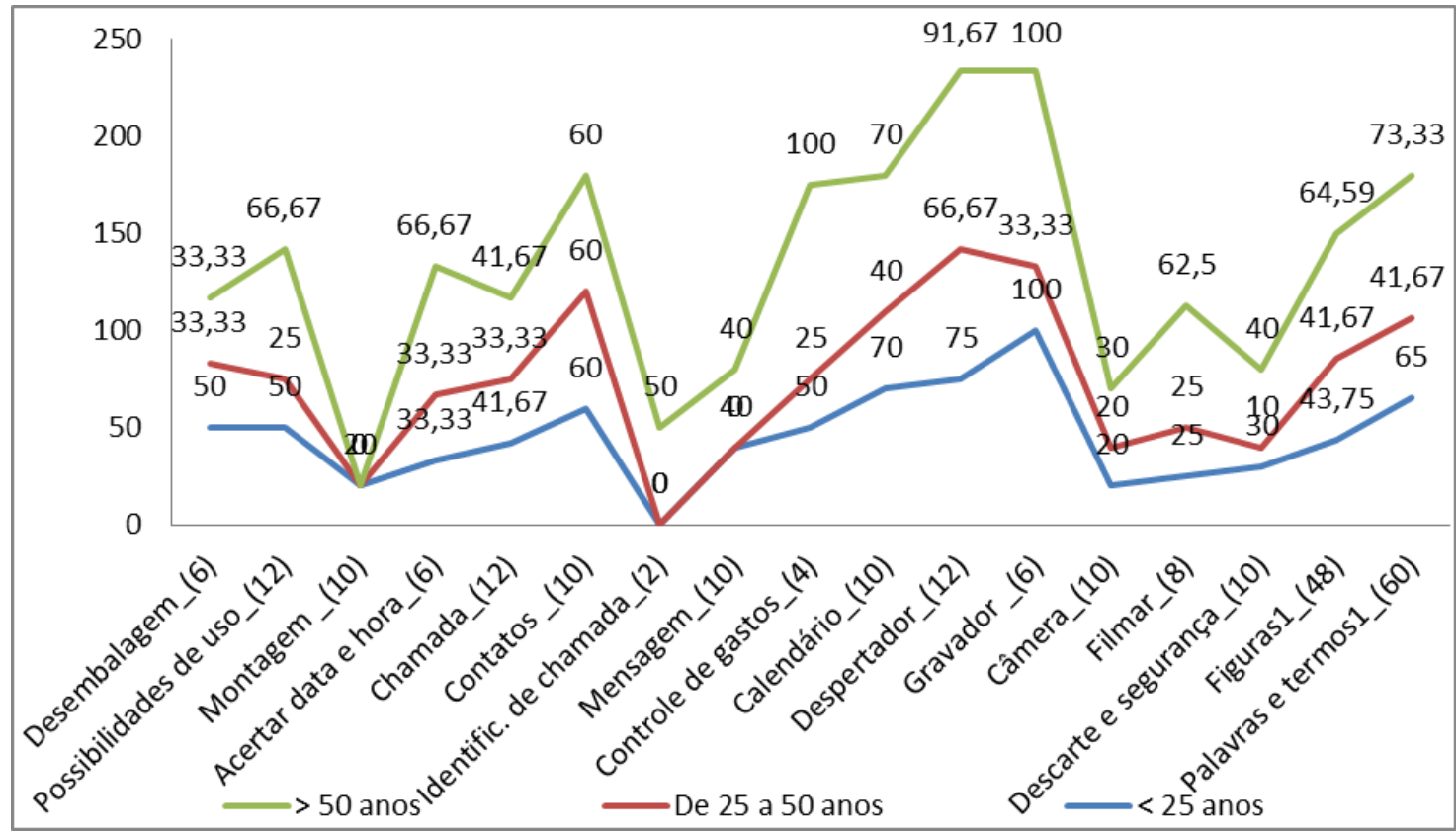

Fonte: Laboratório Interfaces (2009)

A Figura 4 mostra que a ocorrência de erros nas interações dos sujeitos menores de 25 anos com o aparelho celular Motorola predominou nas categorias consideradas como "funcionalidades básicas", quais sejam: "Desembalagem", "Possibilidades de uso", "Contatos" e "Controle de gastos". Com relação às categorias consideradas como "outras funcionalidades", os maiores erros ocorreram em "Calendário", "Despertador", "Gravador" e "Palavras e Termos". Na maioria dos casos, os erros obtidos foram devido a não localização da informação no manual de instruções, não compreensão da informação existente, informações incompletas ou ausência de informação.

A faixa etária compreendida entre 25 e 50 anos obteve índices elevados de maior erro em apenas duas categorias avaliadas, a saber: "Contato" e "Despertador", provenientes de informações incompletas, má localização da 
informação no manual e não compreensão da informação fornecida pelo manual de instruções.

Com relação à faixa etária acima de 50 anos, para as 17 categorias avaliadas, 11 apresentaram índices de maior erro acima de 50\% com destaque para a categoria "Controle de gastos" que obteve $100 \%$ de erro, devido a não compreensão da informação existente no manual e/ou não localização da informação no manual.

Dentre as categorias consideradas como "Outras funcionalidades", destacamse as categorias "Despertador" e "Gravador" com 91,67\% e 100\%, respectivamente de maior erro por causa da não localização da informação no manual; informação existente estar incompleta, isto é, não trazia o passo a passo a ser seguido, apenas dizia que era possível fazer determinada ação.

Para Silva; Bifano e Rocha (2009), existem inúmeros fatores que podem influenciar negativamente um indivíduo ao usar seu produto, por exemplo: dimensões mal planejadas, má configuração, inconsistência das funções atribuídas ao mesmo, comandos mal posicionados ou projetados, entre outros. Há ainda quem recorra aos manuais de instrução, no entanto, estes podem apresentar problemas de interpretação bem como de informações gerando pouca compreensão das mesmas, incompatibilidade entre a quantidade de informações, legibilidade, entre outros.

Observa-se que no caso do aparelho Motorola não se pode afirmar que o grau de dificuldade em interagir com o aparelho e seu respectivo manual de instruções aumentou conforme a idade, pois a faixa etária entre 25 e 50 anos obteve percentual menor de erros $(34,33 \%)$ do que a faixa etária menor de 25 anos $(61,45 \%)$.

\subsubsection{Nokia - 2660}

A Figura 5 mostra a ocorrência de maior erro obtida para todas as faixas etárias participantes do estudo, ao utilizar o aparelho Nokia, seguindo as instruções que o acompanham. 
Figura 5 -Número de ocorrências do grau de dificuldade (Valores Percentuais) em todas as categorias obtidas no teste de precisão de ações para o celular NOKIA, e os respectivos Valores Percentuais, para as faixas etárias: menor que 25 anos, entre 25 e 50 anos e acima de 50 anos

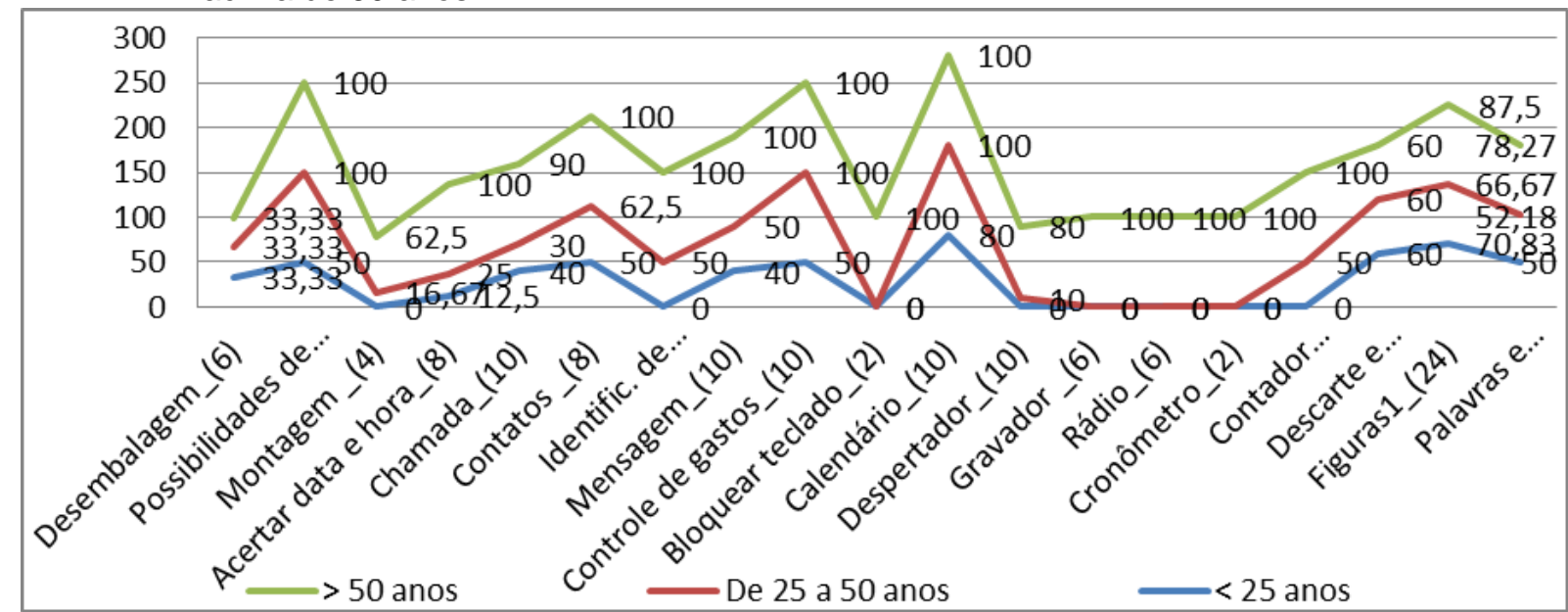

Fonte: Laboratório Interfaces (2009)

Pela Figura 5 observa-se que a ocorrência de maior erro para a faixa etária menor que 25 anos em relação às categorias consideradas como "funcionalidades básicas", foram "Possibilidades de uso", "Contatos" e "Controle de gastos". Em relação às categorias consideradas como "outras funcionalidades", as maiores ocorrências de erro foram em "Calendário", "Descarte e Segurança", "Figuras" e "Palavras e Termos". Na maioria dos casos, essas ocorrências de erro se deram em função da não localização da informação no manual por a mesma estar mal disposta no manual de instruções, não compreensão da informação existente ou mesmo ausência de informações.

A faixa etária de 25 a 50 anos encontrou maiores dificuldades para interagir com o aparelho celular Nokia, faixa etária de maior incidência de ocorrências de maior erro. Dentre as categorias consideradas como "Funcionalidades básicas" os maiores índices de erro se concentraram em "Possibilidades de uso", "Contatos", "Identificação de chamada", "Mensagem" e "Controle de gastos". Já em relação às categorias consideradas como "Outras funcionalidades", os índices de maior erro foram em "Calendário", "Contador regressivo", "Descarte e Segurança", "Figuras" e "Palavras e Termos". Assim como na faixa etária menor que 25 anos, as ocorrências de maior erro foram devido à não localização da informação no manual pela mesma estar mal disposta no manual de instruções, não compreensão da informação existente ou mesmo ausência de informações. 
Observa-se também pela Figura 5 que dentre as 19 categorias avaliadas para o aparelho Nokia, 12 atingiram 100\% de maior erro, para a faixa etária acima de 50 anos, sendo sete nas categorias consideradas "Funcionalidades básicas" e cinco nas categorias consideradas como "Outras funcionalidades", também devido à não localização da informação no manual pela mesma estar mal disposta no manual de instruções, pela não compreensão da informação existente ou mesmo pela ausência de informações.

O mercado está repleto de produtos e sistemas complexos que propõem ao usuário/consumidor, uma variedade de funções. Esta complexificação dos produtos exige, paradoxalmente, que os mesmos sejam de fácil utilização, atendendo à lógica da ampliação constante do mercado consumidor. Para tal, as empresas se utilizam de simulações das possibilidades de uso dos produtos e tentam inserir nos produtos o maior volume possível de informações, quer no próprio desenho, nos símbolos pictóricos, nas etiquetas, em forma de passo a passo, e de manuais de instruções (CHABAUD-RICHTER, 1998). Especificamente, no caso deste último, os manuais de instruções necessitam conter uma série de informações que protejam as empresas de usos "imprevistos" e de riscos de acidentes e, ao mesmo tempo, fornecer informações que contemplem as necessidades de uma variedade de usuários e de contextos de utilização, o que torna produzir instruções uma tarefa complexa.

\subsubsection{Samsung - SGH M310L}

A Figura 6 mostra a ocorrência de maior erro obtida para todas as faixas etárias participantes do estudo, ao utilizar o aparelho Samsung, seguindo as instruções que o acompanham.

O aparelho celular Samsung obteve elevados índices de maior erro ao interagir com os sujeitos das diferentes faixas etárias participantes do estudo. Para a faixa etária menor que 25 anos, os maiores índices de erro foram em relação às categorias "Possibilidades de uso", "Chamada", "Contatos" e "Controle de gastos", consideradas "Funcionalidades básicas do aparelho". As categorias consideradas como "Outras funcionalidades" também obtiveram elevados índices de maior erro, quais sejam: "Calendário", “Despertador", "Gravador”, “Descarte e Segurança” e "Figuras". As ocorrências de erro para esta faixa etária se deram em função da 
ausência de informação, informações incompletas, não localização da informação no manual de instruções e não compreensão da informação existente.

Figura 6 - Número de ocorrências do grau de dificuldade (Percentuais) em todas as categorias obtidas no teste de precisão de ações para o celular SAMSUNG, e os respectivos Valores Percentuais, para as faixas etárias: menor que 25 anos, entre 25 e 50 anos e acima de 50 anos

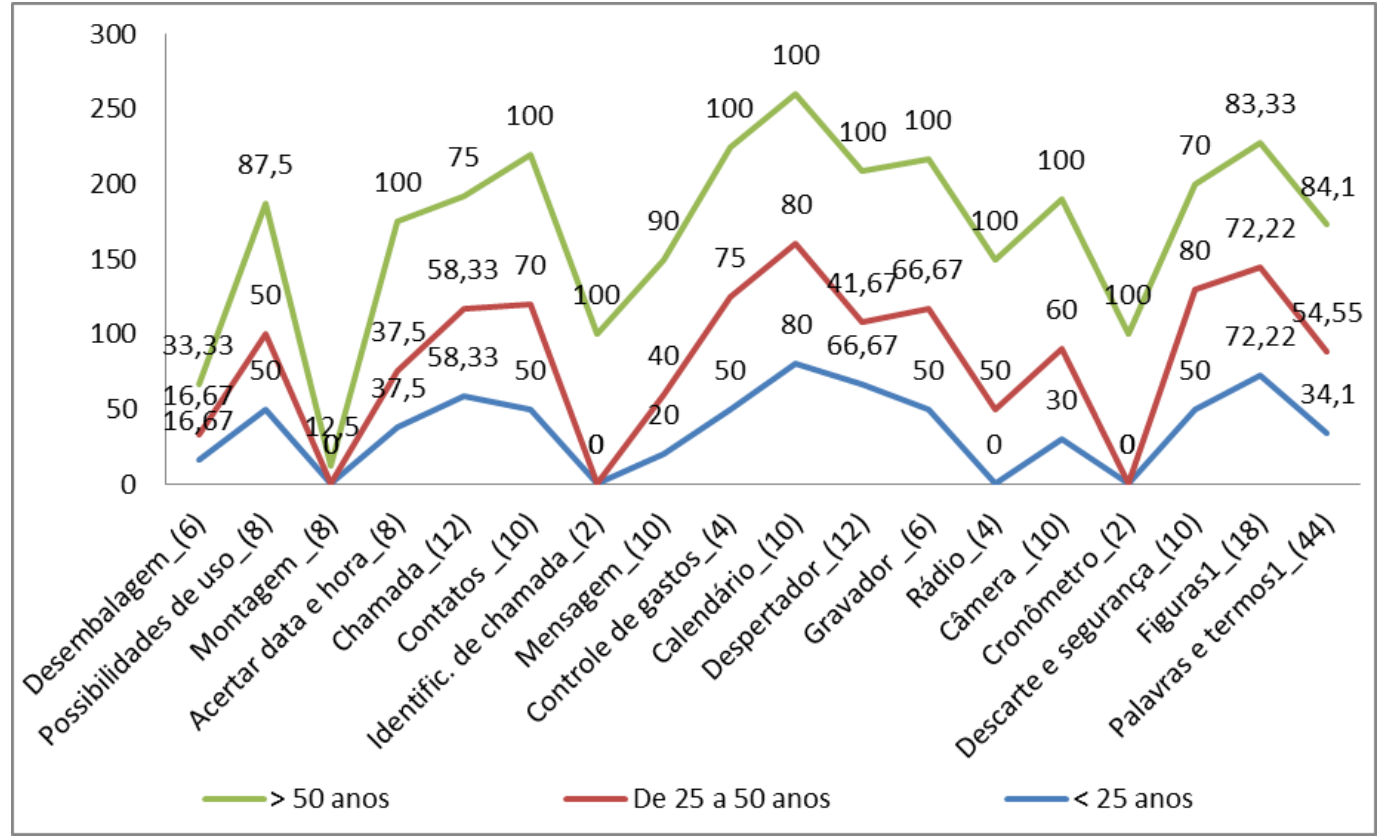

Fonte: Laboratório Interfaces (2009)

$\mathrm{Na}$ faixa etária compreendida entre 25 e 50 anos, as ocorrências de maior erro foram em relação às categorias "Possibilidades de uso", "Chamada", "Contatos" e "Controle de gastos", consideradas como "Funcionalidades básicas". As demais ocorrências de erros foram nas categorias "Calendário", "Gravador", "Rádio", "Câmera", "Descarte e Segurança", "Figuras", "Palavras e Termos", consideradas como "Outras funcionalidades". As ocorrências de erro para esta faixa etária, também, se deram em função da ausência de informação, informações incompletas, não localização da informação no manual de instruções e não compreensão da informação existente.

Nas categorias avaliadas para o aparelho Samsung, 16 apresentaram altos índices de maior erro, para a faixa etária acima de 50 anos, devido ao fato de a maioria das informações contidas no manual de instruções se apresentarem como incompletas e, portanto, insuficientes para a obtenção de êxito nas ações executadas pelos sujeitos acima de 50 anos. 
Dentre as categorias "básicas" destacam-se as categorias "Chamada" e "Mensagem" com 90\% de erros devido à não compreensão da informação disponível e/ou não localização da mesma no manual de instruções, levando os sujeitos maiores de 50 anos a não conseguirem usar estas funcionalidades do aparelho com satisfação.

Para Bifano (2000), o problema não está apenas nas instruções, mas também, nas interpretações e incertezas de uso em situações particulares. Aguiar (2004) ressalta a necessidade de se considerar níveis de experiência diversos entre usuários/consumidores: alguns já utilizaram um produto semelhante; outros não têm nenhuma experiência com determinado produto, como também a utilização tanto de uma lógica de utilização (o usuário/consumidor visa os objetivos e procura os meios para atingi-los) quanto de uma lógica de funcionamento (as regras de desenvolvimento das funcionalidades previstas no produto) na consecução de seus objetivos. A interação dessas duas lógicas, na apresentação do manual, é uma das fontes mais frequentes de dificuldades para os usuários/consumidores. Para Wright (1981), na elaboração de instruções adequadas é necessário avaliar a adequação do conteúdo, da apresentação, da estrutura e a qualidade do escritor.

Outro ponto a ser ressaltado em relação ao aparelho em questão é que todas as categorias consideradas como "Outras funcionalidades" obtiveram 100\% de maior erro, ou seja, nenhum dos sujeitos acima de 50 anos que testou o referido aparelho conseguiu usar as outras funcionalidades do aparelho, seja por não localizar a informação no manual; não compreender a informação fornecida pelo manual ou pelo fato de a maioria das informações existentes no manual estar incompleta, impedindo que os sujeitos obtivessem êxito na utilização do produto.

\subsubsection{Sony Ericsson - W380i}

A Figura 7 mostra a ocorrência de maior erro obtida para todas as faixas etárias participantes do estudo, ao utilizar o aparelho Sony Ericsson, seguindo as instruções que o acompanham.

$\mathrm{Na}$ interação dos sujeitos com o aparelho celular Sony Ericsson ocorreram, também, elevados índices de maior erro para todas as faixas etárias participantes do estudo. Na faixa etária menor que 25 anos, as ocorrências foram relacionadas às 
categorias "Possibilidades de uso", "Acertar data e hora", "Contatos", "Identificação de chamadas" e "Controle de gastos", consideradas como "funcionalidades básicas". Já em relação às categorias consideradas como "outras funcionalidades", os índices elevados de maior erro foram em "Calendário", "MP4", "Rádio" e "Palavras e Termos". Essas ocorrências foram devido à ausência de informação, informações incompletas, não localização da informação no manual de instruções ou não compreensão da informação fornecida pelo manual.

Figura 7 - Número de ocorrências do grau de dificuldade (Valores Absolutos) em todas as categorias obtidas no teste de precisão de ações para o celular SONY ERICSSON, e os respectivos Valores Percentuais, para as faixas etárias: menor que 25 anos, entre 25 e 50 anos e acima de 50 anos

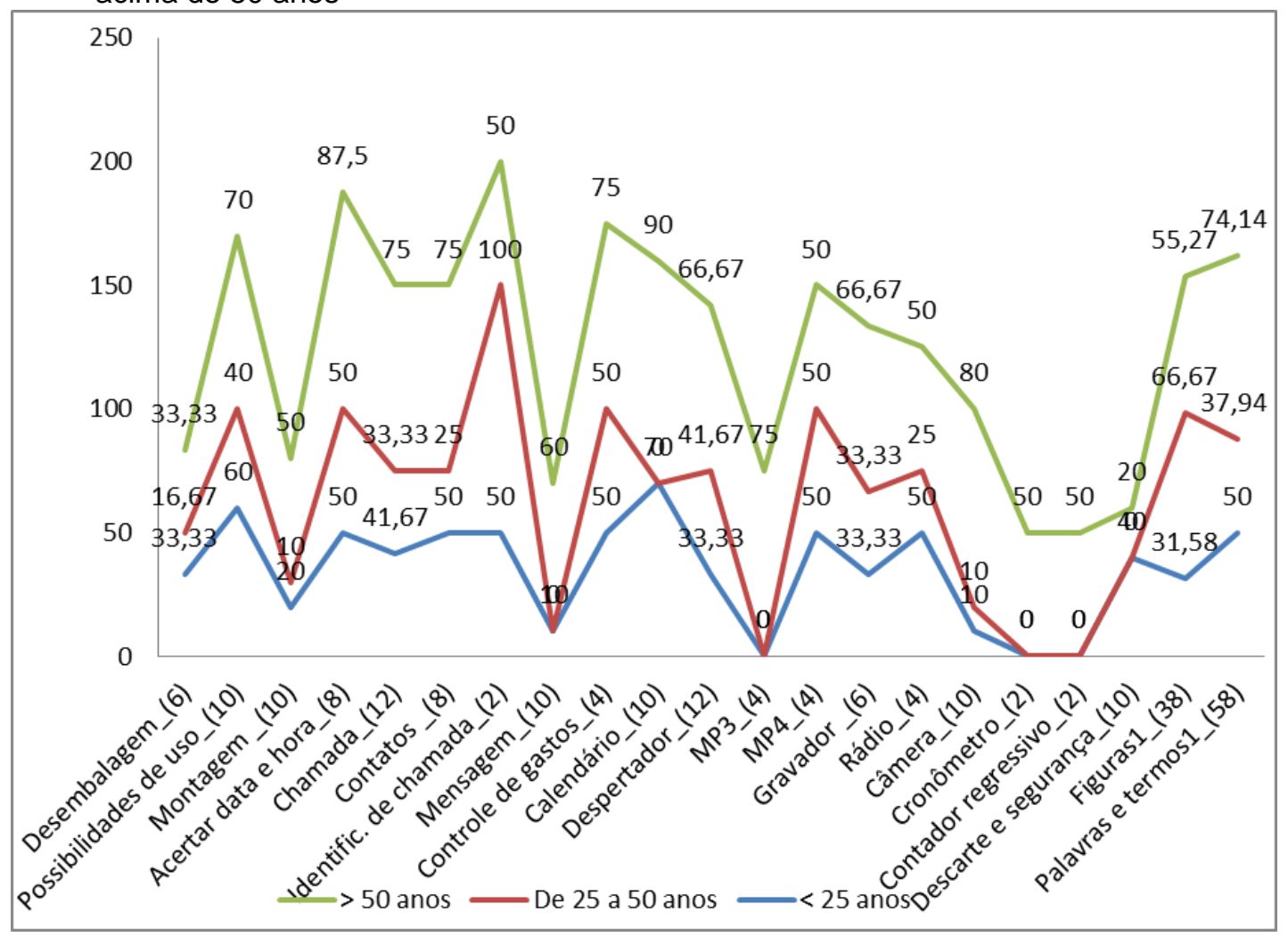

Fonte: Laboratório Interfaces (2009)

Na faixa etária compreendida entre 25 e 50 anos, as ocorrências de maior erro foram em relação às categorias "Acertar data e hora", "Identificação de chamada" e "Controle de gastos", consideradas como "Funcionalidades básicas". Para as categorias consideradas como "Outras funcionalidades", os índices elevados de maior erro foram em "MP4" e "Figuras", erros esses que também ocorreram em função da ausência de informação, informações incompletas, não 
localização da informação no manual de instruções ou não compreensão da informação fornecida pelo manual.

Para o aparelho Sony Ericsson foram avaliadas 21 categorias. Dentre estas apenas duas obtiveram índices relativamente baixos de maior erro, quais sejam: "Desembalagem" e "Descarte e segurança" com 33,33\% e 20\%, respectivamente, para a faixa etária acima de 50 anos.

Dentre as categorias consideradas como "Funcionalidades básicas", destacam-se as categorias "Chamada" e "Contatos" com 75\% de maior erro para cada caso. Esses "erros" se devem aos seguintes motivos: um dos sujeitos não conseguiu inserir o cartão SIM e este aparelho não permite uso sem o chip; não compreensão das informações fornecidas pelo manual e; não localização da informação no manual de instruções.

Dentre as categorias consideradas como "Outras funcionalidades", as categorias "Calendário", "MP3" e "Câmera" destacaram-se por apresentar os índices mais elevados de maior erro, justificados pelo uso de termos desconhecidos pelos sujeitos como handsfree e walkman player, não êxito na inserção do chip no aparelho, informações incompletas e insuficientes e não localização da informação no manual de instruções.

A eficiência da interação usuário/máquina está no fato de a pessoa atingir o objetivo, ou seja, cumprir a tarefa implicada na interpretação humano-máquina objetivamente. Já a eficácia consiste no volume de trabalho que o usuário alcança com o nível mínimo de erro. E o que traz satisfação é o grau de conforto que o usuário sente ao usar um determinado produto atingindo seu objetivo (JORDAN, 1998 apud MORAES, MELO; MACÁRIO., 2002).

Assim como no caso do aparelho Motorola, não se pode afirmar que o grau de dificuldade em interagir com o aparelho Sony Ericsson e seu respectivo manual de instruções aumentou conforme a idade, pois a faixa etária entre 25 e 50 anos obteve percentual menor de erros $(26,53 \%)$ do que a faixa etária menor de 25 anos $(39,14 \%)$.

A Figura 8 apresenta os resultados gerais obtidos para a ocorrência de maior erro nos ensaios, quanto à uniformidade do grau de dificuldade destes sujeitos ao interagir com os manuais de instruções de todos os aparelhos. 
Figura 8 - Número de ocorrência de maior erro por aparelho celular para as diferentes faixas etárias estudadas. Viçosa - MG (2009)

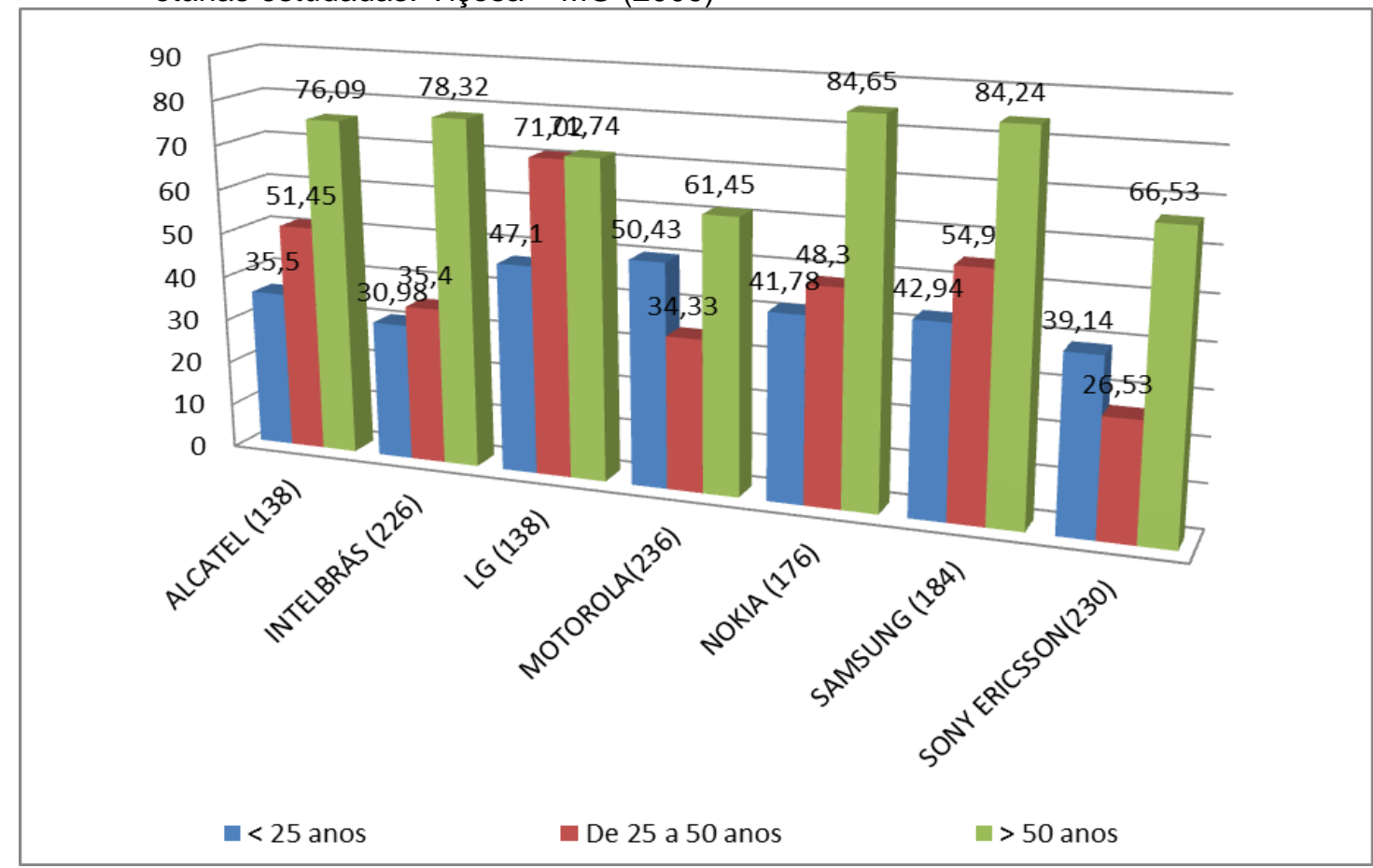

Fonte: Laboratório Interfaces (2009)

Pelos dados da Figura 8 acima verifica-se que a faixa etária menor que 25 anos encontrou maior dificuldade ao interagir com o aparelho celular da marca Motorola $(50,43 \%)$ e menor grau de dificuldade na interação com o aparelho da marca Intelbrás (30,98\%), acompanhados de seus respectivos manuais de instruções.

Já os sujeitos da faixa etária compreendida ente 25 e 50 anos tiveram mais dificuldade para usar o aparelho celular da marca LG $(71,02 \%)$ e menos dificuldade com o aparelho Sony Ericsson (26,53\%).

Observa-se, também, que em relação ao total de variáveis analisadas para cada celular, os resultados para o grupo de sujeitos acima de 50 anos demonstraram que o manual do aparelho celular Motorola foi o de menor ocorrência de maior erro, seguido do Sony Ericsson e LG, com valores entre $60 \%$ e $69 \%$ de ocorrência de erros, ou seja, apesar de serem os menores índices quando comparados aos demais aparelhos, ainda sim, são índices elevados para o uso de manuais de instruções. Os demais se localizaram na faixa acima de $70 \%$.

De acordo com os resultados obtidos, de modo geral, os sujeitos maiores de 50 anos, são mais prejudicados que os demais em suas interações com os manuais e, por consequência, com os seus respectivos aparelhos. É necessário, portanto, um Revista Produção Online, Florianópolis, SC, v. 16, n. 2, p. 441-474, abr./jun. 2016. 
investimento maior nas adequações dos manuais de forma que atendam, também, às necessidades desta faixa etária que tende a crescer em nossa sociedade. Este investimento é, também, uma questão de inclusão social.

\section{CONSIDERAÇÕES FINAIS}

Pôde-se observar que o índice de compreensão errada e não compreensão das informações foi alto para todos os manuais dos aparelhos avaliados.

Os sujeitos participantes do estudo não conseguiram extrair do texto informações subentendidas com relação a determinadas fases do procedimento operacional, pois estas informações não constavam no manual. Observou-se um alto índice tanto de compreensão errada da informação quanto de não compreensão.

Sendo a ausência de informação escrita sobre a forma de efetuar determinada operação e a deficiência das figuras responsáveis pelo alto índice de compreensão errada e não compreensão de determinados procedimentos.

A utilização de termos técnicos desconhecidos pelos sujeitos, também, causou dificuldade para diferenciar entre as funcionalidades indicadas nas etapas de procedimento, o que é muito sério, pois impede o usuário de explorar as várias opções que o produto oferece.

Outro fator relacionado à não compreensão das informações foi a utilização de palavras que adquirem sentido diferenciado na realidade cotidiana dos sujeitos, fazendo com que estes compreendessem as informações de uma maneira diferente daquela pretendida pela equipe de projeto, levando à utilização alternativa de determinadas funções propostas.

Observou-se que, no que diz respeito à qualidade das informações, que estas, por vezes, se apresentaram como imprecisas, no sentido de se caracterizarem como incompreensíveis, por serem difíceis de entender.

Considerando os aspectos apresentados na literatura consultada, pode-se inferir que, com o aumento da população idosa e da expectativa de vida, estes tornam-se consumidores em potencial de produtos, sendo necessário, portanto, que os produtos sejam projetados considerando suas limitações decorrentes do envelhecimento. Acredita-se que, somente assim, o idoso, enquanto consumidor, 
terá sua satisfação atendida, a qual contribuirá de forma significativa para o desenvolvimento de sua autonomia, bem-estar e, consequentemente, melhora da sua auto-estima.

Para tanto se julga imprescindível realizar estudos e pesquisas enfocando a usabilidade de produtos para a população idosa, visto que, são restritos os estudos sobre esse assunto apesar da sua grande relevância, em função do crescente aumento da população idosa no país e no mundo.

Ressalta-se, também, que manuais de instrução são produtos complexos por terem que atender tanto às necessidades das empresas, quanto dos consumidores/usuários dos produtos. Estes últimos, por sua vez, podem escolher uma variedade de maneiras de utilizá-los, a partir de suas experiências anteriores, seu conhecimento prévio a respeito do produto, suas expectativas com relação às funcionalidades, como também características demográficas, tais como sexo, idade e grau de instrução. Entretanto, algumas recomendações podem ser seguidas, como padronização da estruturação dos manuais de instrução; padronização de cores para as interfaces; padronização da forma de escrita e de apresentação de figuras, pictogramas e demais informações.

Os fabricantes precisam pensar em melhorar requisitos de visibilidade e modelo conceitual de seus produtos. Produtos cujos atributos técnicos contemplam o uso cotidiano dos produtos pelas pessoas tendem a propiciar um processo de utilização com número reduzido de lapsos e enganos, e com menor frustração dos sujeitos. Para tanto, se faz necessário compreender a lógica dos usuários potenciais e diminuir a distância existente entre a equipe de P\&D - Pesquisa e Desenvolvimento e os usuários dos produtos.

No caso da população idosa, há que se considerar que, tecnologias que se apresentem como de fácil interação podem ser responsáveis por auxiliar na reconstrução da imagem social da "velhice", na medida em que estes se sintam capazes e incluídos nos avanços tecnológicos mais recentes. Destaca-se que para os idosos, a interação exitosa com as tecnologias pode ser responsável por manter o sentimento de independência e capacidade.

Os requisitos técnicos do produto determinam, até certo ponto, o padrão da interação. Produtos que não oferecem nenhum retorno aos usuários durante sua utilização e não recorrem à "lógicas familiares" aos sujeitos, são mais frustrantes aos

Revista Produção Online, Florianópolis, SC, v. 16, n. 2, p. 441-474, abr./jun. 2016. 
usuários. Atributos técnicos, quando mal projetados, interferem nos esquemas de ação utilizados pelos usuários.

Ressalta-se, também, que é conhecida a complexidade da elaboração de instruções, visto terem que atender às necessidades das empresas, das agências reguladoras e dos consumidores/usuários dos produtos. Estes últimos, por sua vez, podem escolher uma variedade de maneiras de utilizá-los, a partir de suas experiências anteriores, seu conhecimento prévio a respeito do produto, suas expectativas com relação às funcionalidades, como também características demográficas, tais como sexo, idade e grau de instrução. Entretanto, algumas recomendações podem ser seguidas, como padronização da estruturação dos manuais de instrução; padronização de cores para as interfaces; padronização da forma de escrita e de apresentação de figuras, pictogramas e demais informações.

Para a ergonomia, este é um campo de estudos ainda em construção, tanto em termos metodológicos quanto conceituais. É necessário aprofundar o diálogo com as propostas que incluem o estudo da atividade, dando maior ênfase à utilização no mundo real, fora dos espaços de laboratório, para a compreensão das interações usuário/produto inserido nas contingências da vida cotidiana.

\section{REFERÊNCIAS}

AGUIAR, V. C. O desenvolvimento da usabilidade de interfaces em projetos: Um estudo de caso em lavadora de roupa. 2004. 113f. Dissertação (Mestrado em Engenharia de Produção) - Universidade Federal de São Carlos, São Carlos, SP, 2004.

AMARAL JUNIOR, J. C. do. Uso de produtos cotidiano por idosos. 2012. $155 f$. Dissertação (Mestrado em Economia Doméstica) - Universidade Federal de Viçosa, Viçosa, MG , 2012.

BIFANO, A. C. S. Estudo da atividade situada como ferramenta ergonômica para trabalhos de interface. Viçosa, MG: 2000. Universidade Federal de Viçosa, Departamento de Economia Doméstica, 14p.

BIFANO, A. C. S. O produto fala - uma discussão dos aspectos de comunicabilidade inerentes a satisfação de uso. $3^{\circ}$ Congresso Brasileiro de Gestão de Desenvolvimento de Produto, Anais... 2001. Florianópolis: SC, 2001.p.25-27.

BIFANO, A. C. S.; SIMÃO, L. M. Explorando os conceitos da psicologia sóciohistórica como possível contribuição para os trabalhos em interface e usabilidade. 2003. Universidade de São Paulo, São Paulo - SP.

BIFANO, A. C. S.; SZNELWAR, L. I. Estudo introdutório dos conceitos de conhecimento e linguagem enquanto construções sociais na concepção ergonômica das interfaces. XIII 
Congresso Brasileiro de ergonomia; II fórum brasileiro de ergonomia; I Congresso brasileiro de iniciação científica em ergonomia. Anais... 2004. Fortaleza: CE, 2004. P. 62-72.

BIFANO, A. C. S.; SILVA, V. A.; OLIVEIRA, L. A.; ROBERTO, L. C. O Estudo da adequação dos produtos ao uso cotidiano: uma avaliação metodológica. In: XX Congresso Brasileiro de Economia Doméstica, VII Encontro Latino-Americano de Economia Doméstica, I Encontro Intercontinental de Economia Doméstica, Anais...,2009, Fortaleza - CE. Família e Economia Doméstica: Relações, Perspectivas e Desafios. Fortaleza - CE: UFC/DED/ABED, 2009.

BIFANO, A. C. S. SILVA, V. E.; OLIVEIRA, L. A.; ROBERTO, L. C. Análise em manuais de instrução de telefones celulares. 2009. Relatório Técnico de Pesquisa apresentado ao INMETRO.

BIFANO, A. C. S. Análise em manuais de instrução de uso de glicosímetros e seus acessórios, 2013. Relatório Técnico de Pesquisa apresentado à ANVISA/INMETRO.

CANCIGLIERI JUNIOR, O.; BRAMBILLA, E. M.; BITTELBRUNN, C. C. A usabilidade e a ergonomia no suporte às atividades de projeto em desenvolvimento de produtos. XXVII ENCONTRO NACIONAL DE ENGENHARIA DE PRODUÇÃO, Anais... 2007. (pp. 27-39). Foz do Iguaçu: PR.

CARPES Jr, W. P.; SELL, I. O produto como causador de acidentes. Revista Produção Online, v. 4. n. 2, 2004. http://dx.doi.org/10.14488/1676-1901.v4i2.305

CHABAUD-RYCHTER, D. Inovação industrial em eletrodomésticos: concepção de uso e concepção de produção. Revista Latinoamericana de Estudios del Trabajo. v. 4, n. 7, p. 55-76, 1998.

DIAS, C. Avaliação de usabilidade: conceitos e métodos. Disponível em: <http://www.ii.puccampinas.br/revista_ii/Segunda_edicao/Artigo_02/Avaliacao_de_Usabilida de.PDF>. Acesso em: 14 jun. 2008.

FERREIRA, K. G. Teste de Usabilidade. 2002. Monografia (Especialização em Informática), Universidade Federal de Minas Gerais, Belo Horizonte: MG. 2002.

GOMES FILHO, J. Ergonomia do Objeto: sistema técnico de leitura ergonômica. $2^{\circ}$ ed. Revisada e ampliada. São Paulo: Escrituras Editora, 2012.

GOUVINHAS, R. P.; RIBEIRO, M. A.; ROMEIRO FILHO, E. O design universal como abordagem ergonômica na concepção de produtos. $3^{\circ}$ Congresso Brasileiro de Gestão de Desenvolvimento de Produto. Anais. Florianópolis, SC, 2001.

IIDA, I. Ergonomia: projeto e produção. São Paulo: Edgard Blucher. 2005.

INTERNATIONAL ORGANIZATION FOR STANDARDIZATION and INTERNATIONAL ELECTROTECHNICAL COMMISSION, Genève. ISO/IEC GUIDE 37:1995; Instructions for use of products of consumer interest. Genève, 1995. 15p.

MACHADO, T. P. S. O.; ENSSLIN, L.; ENSSLIN, S. R. Desenvolvimento de produtos usando a abordagem MCDA-C.Prod., São Paulo, 2015. Disponível em: $<$ http://www.scielo.br/scielo.php?script=sci_arttext\&pid=S010365132015005062500\&lng=en\&nrm=iso >. Acesso em: 13 ago. 2015. DOI: http://dx.doi.org/10.1590/0103-6513.625AO. 
MARTINEZ, M. L. Um método de Web Design baseado em usabilidade. 16 Simpósio Nacional de Geometria Descritiva e Desenho Técnico; V International Conference on Graphics Engineering for Arts and Design. Anais... 2003 12p. Santa Cruz do Sul RS. Disponível em: < http://www.lsi.usp.br/ martinez/works/_artigos/martinez03a.pdf>. Acesso em: 10 jun. 2008.

MORAES, A.; MELO, C. N. V.; MACARIO, M. Ergonomia e usabilidade - Parâmetros fundamentais para garantir a segurança e o conforto dos usuários. Brasília - Distrito Federal. Pesquisa e Design. Anais... 2002. Disponível em: < http://claudionoronha.googlepages.com/PD200201.doc>. Acesso em: 11 jun. 2008.

MORAES, A.; MELO, C. V.; MACÁRIO, M. Ergonomia e Usabilidade - segurança e conforto dos usuários: produtos perigosos; manuais de instrução. III Ergodesign. Anais... 2003. Rio de Janeiro, RJ. Disponível em: <http://claudionoronha.googlepages.com/3oergodesign.doc>. Acesso em: 11 jun. 2008.

NEVES, C. F; BIFANO, A. C. S. Sistematização teórica sobre a relação entre o idoso as tecnologias no uso cotidiano. I Encontro Interestadual de Engenharia de Produção. EINEPRO, 2015. Anais ... São João da Barra, RJ. 25 a 30 de Abril de 2015.

NIELSEN, J.; MOLICH, R. Heuristic evaluation of user interfaces. In: Proceedings Of The SIGCHI Conference on Human Factors in Computing Systems, p.249-256, 1990. http://dx.doi.org/10.1145/97243.97281

OLIVEIRA, L. A.; BIFANO, A. C. S. Uso de produtos eletrodomésticos por idosos: adequação das informações. GEPROS. Gestão da Produção, Operações e Sistemas, Bauru, V. 9, no 1, p. 41-56, 2014. http://dx.doi.org/10.15675/gepros.v0i1.1140

PINHEIRO, E. J. F. Análise de usabilidade do Pmbok Easy. 2003. Trabalho de graduação em Ciência da Computação. Universidade Federal de Pernambuco. 2003.

SILVA, V. E. ; BIFANO, A. C. S. ; ROCHA, M. . Qualidade das informações que acompanham o produto: Uma avaliação a partir de simulações de uso real. In: XX Congresso Brasileiro de Economia Doméstica, VII Encontro Latino-Americano de Economia Doméstica, I Encontro Intercontinental de Economia Doméstica, 2009, Anais...,Fortaleza CE. Família e Economia Doméstica: Relações, Perspectivas e Desafios. Fortaleza - CE: UFC/DED/ABED, 2009.

SINAIKO, H. W. Verbal factors in human engineering: some cultural and psychological data. In: CHAPANIS, A. Ethnic variables in human factors engineering. Baltimore: John Hapkins UP, 1975. (The Smithsonian Institution. Washington, D. C, paper 16).

SOUZA, V. M. D.; OLIVEIRA, L. A.; BIFANO, A. C. S. Estado da Arte dos estudos de Interface e Usabilidade. In: VI Workshop de Análise Ergonômica do Trabalho; III Encontro Mineiro de Estudos em Ergonomia; VIII SIMPOPET, 2013. Anais..., Viçosa-MG.

TORRES, E.; MAZZONI, A. Conteúdos digitais multimídia: o foco na usabilidade e acessibilidade. Ciência da Informação, Brasília, DF, 2004. p.32-33. Disponível em: <http://www.ibict.br/cienciadainformacao/viewarticle.php?id=320 >. Acesso em: 04 jun. 2008.

VEGINI, D. Modelo de avaliação de desempenho de fogões com foco em ergonomia, utilizando o método MCDA-C. Revista Produção Online, v. 12, n. 2, p. 423-454,2012. http://dx.doi.org/10.14488/1676-1901.v12i2.911 
WRIGHT, P. The Instructions Clearly State. Can't People Read. Applied Ergonomics. 1981. v.12, no 3. 131-141. http://dx.doi.org/10.1016/0003-6870(81)90002-8

WINCKLER, M.; PIMENTA, M. S. Avaliação de usabilidade de sites web. 55p. Disponível em: <http://www.funtec.org.ar/usabilidadsitiosweb.pdf>. Acesso em: 11 jun. 2008.

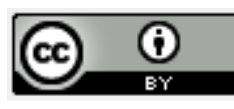

Artigo recebido em 12/08/2014 e aceito para publicação em 16/03/2016

DOI: $\underline{\text { http://dx.doi.org/ 10.14488/1676-1901.v16i2.1860 }}$

Revista Produção Online, Florianópolis, SC, v. 16, n. 2, p. 441-474, abr./jun. 2016. 